\title{
Accelerated hyper-versus normofractionated radiochemotherapy with temozolomide in patients with glioblastoma: a multicenter retrospective analysis
}

\author{
Rainer J. Klement ${ }^{1,2}$ - Ilinca Popp ${ }^{3} \cdot$ David Kaul $^{4,5} \cdot$ Felix Ehret $^{4,6}$ (D) Anca L. Grosu ${ }^{3,7} \cdot$ Bülent Polat $^{8}$. \\ Reinhart A. Sweeney ${ }^{1} \cdot$ Victor Lewitzki $^{8}$ iD
}

Received: 10 November 2021 / Accepted: 6 December 2021 / Published online: 23 December 2021

(c) The Author(s) 2021

\begin{abstract}
Background and purpose The standard treatment of glioblastoma patients consists of surgery followed by normofractionated radiotherapy (NFRT) with concomitant and adjuvant temozolomide chemotherapy. Whether accelerated hyperfractionated radiotherapy (HFRT) yields comparable results to NFRT in combination with temozolomide has only sparsely been investigated. The objective of this study was to compare NFRT with HFRT in a multicenter analysis.

Materials and methods A total of 484 glioblastoma patients from four centers were retrospectively pooled and analyzed. Three-hundred-ten and 174 patients had been treated with NFRT $(30 \times 1.8$ Gy or $30 \times 2$ Gy) and HFRT $(37 \times 1.6$ Gy or $30 \times 1.8 \mathrm{~Gy}$ twice/day), respectively. The primary outcome of interest was overall survival (OS) which was correlated with patient-, tumor- and treatment-related variables via univariable and multivariable Cox frailty models. For multivariable modeling, missing covariates were imputed using multiple imputation by chained equations, and a sensitivity analysis was performed on the complete-cases-only dataset.

Results After a median follow-up of 15.7 months (range 0.8-88.6 months), median OS was 16.9 months (15.0-18.7 months) in the NFRT group and 14.9 months $(13.2-17.3$ months) in the HFRT group $(\mathrm{p}=0.26)$. In multivariable frailty regression, better performance status, gross-total versus not gross-total resection, MGMT hypermethylation, $I D H$ mutation, smaller planning target volume and salvage therapy were significantly associated with longer OS (all $\mathrm{p}<0.01$ ). Treatment differences (HFRT versus NFRT) had no significant effect on OS in either univariable or multivariable analysis.

Conclusions Since HFRT with temozolomide was not associated with worse OS, we assume HFRT to be a potential option for patients wishing to shorten their treatment time.
\end{abstract}

Keywords Accelerated hyperfractionation $\cdot$ Altered fractionation $\cdot$ Glioblastoma $\cdot$ Radiotherapy $\cdot$ Temozolomide

Rainer J. Klement

rainer_klement@gmx.de

$\triangle$ Victor Lewitzki

lewitzki_v@ukw.de

David Kaul

david.kaul@charite.de

Felix Ehret

felix.ehret@charite.de

1 Klinik für Strahlentherapie, Leopoldina Krankenhaus Schweinfurt, MVZ Leopoldina Krankenhaus,

Robert-Koch-Straße 10, 97422 Schweinfurt, Germany

2 Klinik für Radio-Onkologie, Universitätsspital Zürich, Universität Zürich, 8006 Zurich, Switzerland

3 Klinik für Strahlenheilkunde, Universitätsklinikum Freiburg, 79106 Freiburg, Germany
4 Klinik Für Radioonkologie und Strahlentherapie, Charité - Universitätsmedizin Berlin, 13353 Berlin, Germany

5 German Cancer Consortium (DKTK), partner site Berlin, Berlin, Germany

6 Berlin Institute of Health at Charité - Universitätsmedizin Berlin, 10117 Berlin, Germany

7 German Cancer Consortium (DKTK), Partner Site Freiburg, German Cancer Research Center (DKFZ), Heidelberg, Germany

8 Klinik für Strahlentherapie und Radioonkologie, Universitätsklinikum Würzburg, Josef-Schneider-Straße 11, 97080 Würzburg, Germany 


\section{Abbreviations}

GB Glioblastoma

HFRT Hyperfractionated radiotherapy

NFRT Normofractionated radiotherapy

PTV Planning target volume

TMZ Temozolomide

\section{Introduction}

Glioblastoma (GB) is the most common malignant tumor of the central nervous system in adults [1], accounting for approximately $69 \%$ of all malignant adult brain tumors in Germany [2]. The prognosis remains dismal, with a median overall survival (OS) for the whole patient population below 21 months and 5-year OS rates below 10\% after standardof-care trimodal therapy, consisting of surgery followed by radiotherapy with concomitant and adjuvant temozolomide (TMZ) chemotherapy [3-5].

Prognostic factors for patients with GB are related to patient-, treatment- and tumor characteristics. Patient-related prognostic factors include age at diagnosis, clinical and neurological performance at diagnosis or recurrence [6-9], as well as body mass index [10-12], and blood glucose levels [13-17]. Treatment-related factors include gross total resection, concomitant and adjuvant use of TMZ, tumortreating fields, and aggressive salvage therapy (if possible) [4, 18-21]. Molecular factors include methylation status of the $\mathrm{O}^{6}$-methylguanine-DNA methyltransferase (MGMT) promoter [22] and mutation status of isocitrate dehydrogenase 1 and $2(I D H ~ 1 / 2)$ [23-25]. The role of telomerase reverse transcriptase (TERT) promoter mutation remains ambiguous to this date $[26,27]$.

The analysis of Brain Tumor Study Group protocols (1966-1975) revealed a radiotherapeutic dose-effect relationship [28], suggesting dose escalation as a viable possibility of treatment optimization. The main focus of accelerated hyperfractionated radiotherapy (HFRT) was to exploit the differences in redistribution, reoxygenation, repopulation, and DNA damage repair between normal and tumor cells $[29,30]$ on the way to dose escalation.

Several prospective glioma trials from the pre-TMZ era have evaluated the potential of HFRT [31-34]. HFRT with or without dose escalation however failed to show any superiority in OS or progression-free survival (PFS) in comparison to normofractionated radiotherapy (NFRT) [35]. A more recently published randomized controlled trial comparing chemo-radiation protocols of dose escalated HFRT with NFRT did not point towards any benefit of HFRT in terms of OS [36].

In addition to the evidence for non-inferiority of HFRT in the abovementioned trials, HFRT schemes significantly reduce treatment time, even though the absolute number of radiotherapy treatments is higher in NFRT schemes. Therefore, the rationale to use it as an alternative scheme for patients is to shorten the time of irradiation from 6 to less than 4 weeks. Furthermore, radiobiologists have hypothesized a reduction of late radiation injury as well as reduced repopulation rates in tumor cells [37]. The current treatment standard for primary GB is the combination of radiotherapy and TMZ according to the Stupp protocol [38] plus an eventual adjuvant therapy with tumor treating fields which may add a few months to the PFS and OS [4]. To the best of our knowledge, there are no prospective randomized trials investigating the efficacy of HFRT versus NFRT in combination with TMZ, with only a couple of monocentric retrospective studies reporting comparable outcomes [39, 40]. To further explore any differences that might exist between HFRT and NFRT, we performed a retrospective multicenter analysis of GB patients which allowed us to model the effects of both schemes on PFS and OS while accounting for known prognostic factors.

\section{Materials and methods}

This work is based on data of patients with newly diagnosed GB treated from $10 / 2004$ to $7 / 2018$ at four tertiary care institutions. Variables of interest were retrospectively collected by each center and inserted into a Microsoft ${ }^{\circledR}$ Access database, which contained pre-specified selection possibilities for the value assignment of categorical variables. The anonymized center-specific databases were then exported and pooled into a single Microsoft ${ }^{\circledR}$ Excel file, which was further processed with R statistical software.

Inclusion criteria for this analysis were at least one follow-up of OS, age $\geq 18$ years and having received either HFRT $(37 \times 1.6$ Gy or $30 \times 1.8$ Gy twice/day) or NFRT $(30 \times 1.8 \mathrm{~Gy}, 30 \times 2 \mathrm{~Gy}$ or $30 \times 1.8 \mathrm{~Gy}$ with $2 \mathrm{~Gy}$ simultaneously integrated boost). This resulted in 484 patients being eligible for analysis of which 310 had received NFRT and 174 HFRT. Differences between the NFRT and HFRT group were assessed using the Wilcoxon rank sum test and Fisher's exact test for continuous and categorical variables, respectively. PFS was calculated as the time difference between the start of treatment and first clinical or radiological progression. The latter had to be confirmed according to the Response Assessment in Neuro-Oncology (RANO) criteria [41] by a board-certified neuroradiologist. Follow-up included clinical and radiological evaluation every 3 months or depending on the patients' performance status. Salvage treatment was defined as any treatment initiated after tumor progression (repeat irradiation, surgery, bevacizumab, TMZ, and combinations thereof).

The primary outcome of interest for this study was OS, with PFS as a secondary outcome, both calculated according 
to the Kaplan-Meier method. PFS and OS were correlated with patient-, tumor- and treatment-related variables via univariable and multivariable Cox frailty models. The frailty model accounts for clustering of patients within centers and therefore for any unmeasured center-specific factors that may affect the outcome (e.g. patient selection bias) [42, 43]. The Cox frailty model can be written as

$h_{i}(t)=h_{0}(t) \exp \left(\boldsymbol{X}_{i} \beta+\alpha_{j}\right)=h_{0}(t) \exp \left(\alpha_{j}\right) \exp \left(\boldsymbol{X}_{i} \beta\right)$

where $\boldsymbol{X}_{i}$ is a vector of covariates for patient $i, h_{0}(t)$ the baseline hazard function and $\alpha_{j}$ is the random effect associated with the $j$-th cluster (clinic) that acts as a multiplier on the baseline hazard. A log-normal distribution was assumed for the frailty terms, equivalent to a normal distribution of the random effects $\exp \left(\alpha_{j}\right)$.

For multivariable modelling, we tried to utilize as many variables as possible $[44,45]$ by imputing the covariates with missing information using the multiple imputation by chained equations R package 'mice' [46]. A "missing at random" mechanism was assumed being responsible for missing variables, with all variables given in Table 1 as well as follow-up time and OS being added into the imputation model. Variables were imputed in the order of their number of missing cases. Logistic regression and predictive mean matching were used for imputing binary and continuous variables, respectively. A total of 100 imputation data sets were created. Each was used to fit a Cox frailty regression model, and the final Cox model was obtained by pooling the coefficients of these 100 Cox models together. For sensitivity analysis, a Cox model using only the complete cases (with no missing values) was built and compared to the Cox model resulting from the imputed datasets.

Statistical significance was defined as p-values $<0.01$. This threshold was chosen based on the conversion between p-values and minimum Bayes factors [47]. Bayes factors (or likelihood ratios in case of simple hypotheses) measure the strength of evidence between two competing hypotheses [48]. In exploratory analyses, a p-value of 0.01 corresponds to a minimum Bayes factor of $1 / 6.5$, providing moderatestrong evidence against the null hypothesis [47]. All analyses were performed within the statistical programming language $\mathrm{R}$ version 4.0.3 [49].

\section{Results}

Table 1 shows the baseline characteristics of the 484 patients fulfilling the inclusion criteria for this study. There was a significant difference between the NFRT and HFRT group with respect to the treating institution, because HFRT patients mainly stemmed from two hospitals. Other significant differences between the NFRT and HFRT groups existed for planning target volume (PTV) (larger in the HFRT group), steroid administration (more frequent in the HFRT group), and salvage treatment (less frequent in the HFRT group). The exact form of salvage treatment was known for 266 patients and most frequently consisted of surgery (23.3\% of cases), repeat radiotherapy (16.5\%), TMZ (16.2\%), and the combination of surgery and TMZ (14.3\%).

Kaplan-Meier survival curves stratified according to treatment protocol are shown in Fig. 1. Median follow-up for the whole cohort was 15.7 months (range 0.8-88.6 months). During individual follow-up, tumor progression occurred in 385 out of 410 patients (it was unknown for 74 patients), and 394 of the 484 patients had died. Median PFS was 10.0 months (95\% confidence interval [CI] 9.2-11.0) in the NFRT group and 7.9 months (6.6-9.3 months) in the HFRT group, which was almost significantly different $(\mathrm{p}=0.012)$. Median OS was 16.9 months (15.0-18.7 months) in the NFRT group and 14.9 months (13.2-17.3 months) in the HFRT group $(\mathrm{p}=0.26)$. OS was 16.0 months in both groups combined (95\% CI 15.0-17.6 months).

A difference in PFS and OS between centers was evident from univariable Cox regression analysis (Table 2). Given that these differences might reflect differences in some unmeasured hospital-specific variables, frailty models were used to fit the other univariable models reported in Table 2. Factors significantly associated with longer PFS were higher KPS, frontal versus multifocal tumor location, gross total resection, $M G M T$ hypermethylation, $I D H$ mutation and simultaneous plus sequential TMZ versus no TMZ administration. Factors significantly associated with longer OS were younger age, higher KPS, frontal versus multifocal tumor location, gross total resection, MGMT hypermethylation, $I D H$ mutation, simultaneous plus sequential TMZ versus no TMZ administration, no steroid administration and salvage treatment.

After creating 100 imputation datasets, we fitted a separate multivariable Cox frailty model to each of these datasets and pooled the regression coefficients and associated $\mathrm{p}$-values. The average hazard ratios and $\mathrm{p}$-values are given in Table 3. After controlling for many possible confounders, higher KPS, gross total versus not gross total resection, MGMT hypermethylation, $I D H$ mutation, smaller PTV size and salvage therapy were significantly associated with longer OS (all $\mathrm{p}<0.01$ ). RT schedule (HFRT versus NFRT) had no significant effect on OS $(p=0.108)$. Also, in contrast to univariable analysis, multifocal disease was no longer associated with worse OS. The frailty term modelling heterogeneity between hospitals was on the threshold of statistical significance $(p=0.010)$, showing the importance of its inclusion into the model.

A multivariable Cox model fit to the original dataset with complete observations only resulted in similar hazard ratios (Table 4). However, the uncertainties were larger due to 
Table 1 Baseline characteristics

\begin{tabular}{|c|c|c|c|c|c|}
\hline Variable & Unit & Overall cohort $(\mathrm{N}=484)$ & NFRT $(\mathrm{N}=310)$ & $\operatorname{HFRT}(\mathrm{N}=174)$ & p-value \\
\hline \multirow[t]{4}{*}{ Clinic } & Würzburg & $149(30.8 \%)$ & $39(12.6 \%)$ & $110(63.2 \%)$ & \multirow[t]{4}{*}{$<0.0001^{*}$} \\
\hline & Freiburg & $135(27.9 \%)$ & $135(43.5 \%)$ & 0 & \\
\hline & Berlin & $129(26.6 \%)$ & $67(21.6 \%)$ & $62(35.6 \%)$ & \\
\hline & Schweinfurt & $71(14.7 \%)$ & $69(22.3 \%)$ & $2(1.2 \%)$ & \\
\hline Age & Years: Median (range) & $60(22-85)$ & $61(23-85)$ & $59(22-81)$ & 0.098 \\
\hline \multirow[t]{2}{*}{ Gender } & Female & $186(38.4 \%)$ & $122(39.4 \%)$ & $64(36.8 \%)$ & \multirow[t]{2}{*}{0.627} \\
\hline & Male & $298(61.6 \%)$ & $188(60.6 \%)$ & $110(63.2 \%)$ & \\
\hline \multirow[t]{2}{*}{ KPS } & Median (range) & $80(40-100)$ & $80(40-100)$ & $80(40-100)$ & \multirow[t]{2}{*}{0.222} \\
\hline & Unknown & 2 & 2 & 0 & \\
\hline \multirow[t]{5}{*}{ Main tumor localization } & Frontal & $132(27.3 \%)$ & $73(23.5 \%)$ & $59(33.9 \%)$ & \multirow[t]{5}{*}{0.019} \\
\hline & Parietal & $89(18.4 \%)$ & $51(16.5 \%)$ & $38(21.8 \%)$ & \\
\hline & Temporal & $138(28.5 \%)$ & 99 (31.9) & $39(22.4 \%)$ & \\
\hline & Multifocal & $78(16.1 \%)$ & $56(18.1 \%)$ & $22(12.6 \%)$ & \\
\hline & Other & $47(9.7 \%)$ & $31(10 \%)$ & $16(9.2 \%)$ & \\
\hline \multirow[t]{5}{*}{ Surgery extent } & Complete resection & $186(39.7 \%)$ & $121(40.6 \%)$ & $65(38.0 \%)$ & \multirow[t]{5}{*}{0.088} \\
\hline & Incomplete resection & $179(38.2 \%)$ & $117(39.3 \%)$ & $62(36.3 \%)$ & \\
\hline & Debulking & $25(5.3 \%)$ & $19(6.4 \%)$ & $6(3.5 \%)$ & \\
\hline & Biopsy & $79(16.8 \%)$ & $41(13.7 \%)$ & $38(22.2 \%)$ & \\
\hline & Unknown & 15 & 12 & 3 & \\
\hline \multirow[t]{3}{*}{ Complete resection } & No & $283(60.3 \%)$ & $177(59.4 \%)$ & $106(62.0 \%)$ & \multirow[t]{3}{*}{0.897} \\
\hline & Yes & $186(39.7 \%)$ & $121(40.6 \%)$ & $65(38.0 \%)$ & \\
\hline & Unknown & 15 & 12 & 3 & \\
\hline \multirow[t]{3}{*}{ MGMT hypermethylation } & No & $189(54.0 \%)$ & $125(54.3 \%)$ & $64(53.3 \%)$ & \multirow[t]{3}{*}{0.910} \\
\hline & Yes & $161(46.0 \%)$ & $105(45.7 \%)$ & $56(46.7 \%)$ & \\
\hline & Unknown & 134 & 80 & 54 & \\
\hline \multirow[t]{3}{*}{ IDH mutation } & No & $308(91.4 \%)$ & $216(90.8 \%)$ & $92(92.9 \%)$ & \multirow[t]{3}{*}{0.748} \\
\hline & Yes & $29(8.6 \%)$ & $22(9.2 \%)$ & $7(7.1 \%)$ & \\
\hline & Unknown & 147 & 72 & 75 & \\
\hline \multirow[t]{2}{*}{ PTV } & $\mathrm{ccm}^{3}:$ Median (range) & $272(31-1576)$ & $264(31-1576)$ & $293(61-771)$ & \multirow[t]{2}{*}{$0.0071^{*}$} \\
\hline & Unknown & 33 & 19 & 14 & \\
\hline \multirow[t]{5}{*}{ Temozolomide } & No & $30(6.2 \%)$ & $25(8.1 \%)$ & $5(2.9 \%)$ & \multirow[t]{5}{*}{0.121} \\
\hline & Simultaneous & $46(9.5 \%)$ & $27(8.7 \%)$ & $19(10.9 \%)$ & \\
\hline & Simultaneous + sequential & $399(82.4 \%)$ & $252(81.3 \%)$ & $147(84.5 \%)$ & \\
\hline & Sequential & $7(1.4 \%)$ & $4(1.3 \%)$ & $3(1.7 \%)$ & \\
\hline & Other & $2(0.4 \%)$ & $2(0.6 \%)$ & 0 & \\
\hline \multirow[t]{3}{*}{ Concomitant steroids } & No & $170(37.4 \%)$ & $132(44.7 \%)$ & $38(23.9 \%)$ & \multirow[t]{3}{*}{$<0.0001 *$} \\
\hline & Yes & $284(62.6 \%)$ & $163(55.3 \%)$ & $121(76.1 \%)$ & \\
\hline & Unknown & 30 & 15 & 15 & \\
\hline \multirow[t]{3}{*}{ Salvage treatment } & No & $169(38.8 \%)$ & $96(33.4 \%)$ & $73(49.0 \%)$ & \multirow[t]{3}{*}{$0.0019 *$} \\
\hline & Yes & $267(61.2 \%)$ & $191(66.6 \%)$ & $76(51.0 \%)$ & \\
\hline & Unknown & 48 & 23 & 25 & \\
\hline
\end{tabular}

Differences between the NFRT and HFRT groups were assessed using the Wilcoxon and Fisher's exact test for continuous and categorical variables, respectively

$* \mathrm{p}<0.01$ (statistically significant)

the smaller number of observed events (258 patients were not considered due to missing variables), and only MGMT hypermethylation, surgery extent, PTV size, and salvage therapy reached the threshold of statistical significance $(\mathrm{p}<0.01)$. 

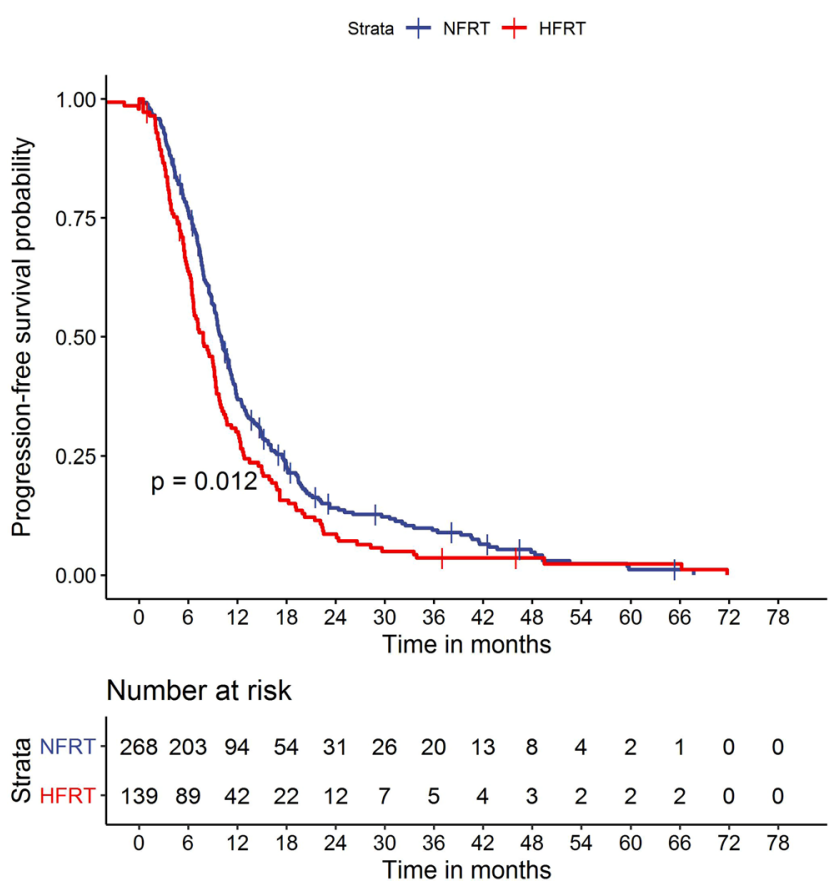

Fig. 1 Progression-free and overall survival probability as a function of follow-up time computed with the Kaplan-Meier estimator and stratified according to treatment schedule (statistical significance at

\section{Discussion}

The main aim of this study was to compare patients who had received HFRT with those having received NFRT with respect to PFS and OS. The strength of this analysis is that patients were pooled from four different hospitals, resulting in a large cohort of 484 patients for which several putatively prognostic factors were known. The analysis indicates that HFRT yielded comparable outcomes to NFRT.

This confirms previous findings that accelerated HFRT achieves treatment effects comparable to NFRT in a shorter time frame $[39,40]$. The lower $\alpha / \beta$ ratio of normal brain tissue for late reactions, for which an $\alpha / \beta$ value of $2 \mathrm{~Gy}$ is widely accepted, favors a hyperfractionated acceleration instead of a hypofractionated one. The biologically effective dose (BED) inside the tumor of HFRT protocols may vary considerably because of uncertainties about the kick-off time when repopulation sets in, $T_{k}$, and the doubling time $T_{d}$ of repopulation. Radiobiological estimates for GB resulted in $T_{k}=37$ days and $T_{d}=15.4$ days, indicating a negligible influence of fractionation, but these estimates were obtained based on PFS rather than on the more reliable endpoint OS [50]. Using the formula provided by Lee et al. [51]
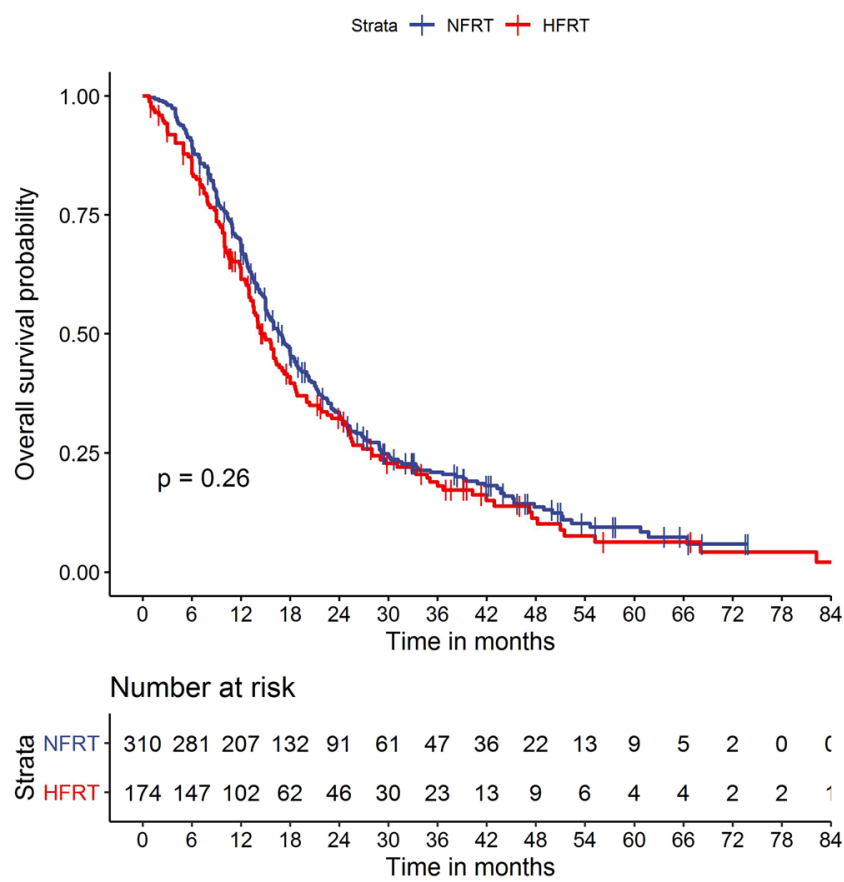

$\mathrm{p}<0.01)$. HFRT: Hyperfractionated radiotherapy NFRT: Normofractionated radiotherapy

$$
\mathrm{BED}=\left\{\begin{array}{l}
n d\left(1+\frac{d}{\alpha / \beta}\right), \quad T \leq T_{k} \\
n d\left(1+\frac{d}{\alpha / \beta}\right)-\frac{\ln 2\left(T-T_{k}\right)}{\alpha \cdot T_{d}}, \quad T>T_{k}
\end{array}\right.
$$

and adopting $\alpha / \beta=8$ Gy and $\alpha=0.12 \mathrm{~Gy}^{-1}$ for GB [50], we calculated BEDs for the different schemes as follows:

- $30 \times 1.8 \mathrm{~Gy}$ twice/day $(T=21$ days): $\mathrm{BED}=66.2 \mathrm{~Gy}$;

- $37 \times 1.6$ Gy twice/day ( $T=24.5$ days $): \mathrm{BED}=71.0 \mathrm{~Gy}$;

- $30 \times 2$ Gy daily ( $T=42$ days): $\mathrm{BED}=73.1 \mathrm{~Gy}$.

Thus, the BEDs of the three different schedules are not too different and-given an additional clonal heterogeneity and clonal selection by radiotherapy-may explain why the particular fractionation scheme had no significant effect on PFS or OS.

To the best of our knowledge, there was no favorable patient selection for HFRT protocols. Quite opposite, in one center (center 3) the HFRT scheme was preferably used in patients with involvement of or a tumor position close to the brain stem; this was also the case in some patients from center 1. Furthermore, some of the prognostic factors indicated a less favorable patient selection into the HFRT group: A significantly higher percentage of patients did 
Table 2 Results of the univariable Cox frailty model analyses

\begin{tabular}{|c|c|c|c|c|c|c|c|c|}
\hline \multirow[t]{3}{*}{ Variable } & \multicolumn{4}{|l|}{ PFS } & \multicolumn{4}{|c|}{ Overall survival } \\
\hline & \multirow[t]{2}{*}{ HR } & \multicolumn{2}{|l|}{$95 \% \mathrm{CI}$} & \multirow[t]{2}{*}{ p-value } & \multirow[t]{2}{*}{ HR } & \multicolumn{2}{|l|}{$95 \% \mathrm{CI}$} & \multirow[t]{2}{*}{ p-value } \\
\hline & & Lower & Upper & & & Lower & Upper & \\
\hline Clinic & & & & & & & & 0.273 \\
\hline Clinic 2 vs. Clinic 1 & 1.059 & 0.813 & 1.380 & 0.672 & 1.155 & 0.893 & 1.494 & \\
\hline Clinic 3 vs. Clinic 1 & 1.658 & 1.278 & 2.152 & $0.0014 *$ & 1.925 & 1.471 & 2.520 & $<0.0001 *$ \\
\hline Clinic 4 vs. Clinic 1 & 0.601 & 0.423 & 0.854 & $0.0045^{*}$ & 1.113 & 0.806 & 1.537 & 0.516 \\
\hline RT-protocol: HFRT vs NFRT & 1.213 & 0.933 & 1.577 & 0.149 & 1.258 & 0.963 & 1.644 & 0.093 \\
\hline Age (10 years increase) & 1.144 & 1.036 & 1.263 & $0.0078 *$ & 1.255 & 1.143 & 1.379 & $<0.0001 *$ \\
\hline Gender: Female vs. Male & 1.203 & 0.975 & 1.483 & 0.085 & 1.394 & 1.131 & 1.719 & $0.0019 *$ \\
\hline KPS & 0.980 & 0.971 & 0.989 & $<0.0001^{*}$ & 0.975 & 0.967 & 0.984 & $<0.0001 *$ \\
\hline \multicolumn{9}{|l|}{ Main tumor localization } \\
\hline Parietal vs. Frontal & 0.870 & 0.642 & 1.179 & 0.370 & 0.820 & 0.606 & 1.110 & 0.200 \\
\hline Temporal vs. Frontal & 0.840 & 0.639 & 1.105 & 0.213 & 0.849 & 0.647 & 1.114 & 0.238 \\
\hline Multifocal vs. Frontal & 1.567 & 1.118 & 2.196 & $0.0092 *$ & 1.713 & 1.245 & 2.357 & $0.00094 *$ \\
\hline Other vs. Frontal & 1.010 & 0.695 & 1.467 & 0.960 & 1.197 & 0.830 & 1.724 & 0.336 \\
\hline $\begin{array}{l}\text { Surgery extent: Gross total vs. not gross } \\
\text { total resection }^{\text {a }}\end{array}$ & 0.695 & 0.564 & 0.858 & $0.00070^{*}$ & 0.569 & 0.461 & 0.703 & $<0.0001^{*}$ \\
\hline MGMT hypermethylation: Yes vs. No & 0.456 & 0.354 & 0.587 & $<0.0001^{*}$ & 0.426 & 0.330 & 0.551 & $<0.0001^{*}$ \\
\hline IDH mutation: Yes vs. No & 0.442 & 0.263 & 0.742 & $0.0020 *$ & 0.249 & 0.132 & 0.472 & $<0.0001 *$ \\
\hline PTV (100 $\mathrm{cm}^{3}$ increase $)$ & 1.062 & 0.992 & 1.136 & 0.084 & 1.131 & 1.064 & 1.203 & $<0.0001 *$ \\
\hline \multicolumn{9}{|l|}{ Temozolomide } \\
\hline Simultaneous + sequential vs. none & 0.500 & 0.322 & 0.777 & $0.0021^{*}$ & 0.307 & 0.207 & 0.455 & $<0.0001 *$ \\
\hline Simultaneous or sequential vs. none & 0.787 & 0.441 & 1.402 & 0.416 & 0.656 & 0.406 & 1.060 & 0.085 \\
\hline Steroids: Yes vs. No & 1.375 & 1.068 & 1.770 & 0.014 & 1.948 & 1.549 & 2.450 & $<0.0001 *$ \\
\hline Salvage: Yes vs. No ${ }^{\mathrm{b}}$ & - & - & - & - & 0.531 & 0.426 & 0.663 & $<0.0001 *$ \\
\hline
\end{tabular}

Frailty models accounting for clustering of patients within hospitals were fitted except for the model including clinic as the dependent variable CI confidence interval; HR hazard ratio; PFS progression-free survival

${ }^{a}$ Not gross total resection comprises incomplete resection, debulking and biopsy

${ }^{\mathrm{b}}$ Salvage therapy always provided after tumor progression, therefore no evaluation

receive concomitant steroids (76.1\% versus $55.3 \%$, Table 1$)$, which is associated with poorer OS [52]. PTV sizes were also larger in the HFRT group, and a significantly lower percentage of patients received salvage therapy after tumor progression. For these reasons, we performed multivariable regression analysis with frailty terms in order to reduce any possible selection bias that is a general problem of retrospective analyses.

We were able to confirm the effect of several prognostic factors in univariable and multivariable analysis. The significant predictors were gross total versus non-gross total resection, MGMT hypermethylation, $I D H$ mutation status, and salvage treatment. Mutations in the $I D H 1$ or IDH2 gene may predict a better prognosis by downregulating several hypoxia-inducible factor $1 \alpha$ (HIF-1 $\alpha$ ) target genes which are involved in glycolytic energy metabolism [53], among them lactate dehydrogenase (LDH) which catalyzes the conversion of pyruvate to lactate and thereby contributes to the acidification of the tumor microenvironment [54]. Accordingly, the LDH serum concentration was shown to be negatively correlated to OS in GB patients [33]. Both univariable and multivariable analyses also showed that OS was comparable between the HFRT and NFRT groups. However, there was a trend towards different PFS rates between the two groups, eventually pointing towards a systematic difference between centers in the evaluation of PFS within the scope of the RANO guidelines. The differentiation between pseudo-progression and real tumor regrowth is a difficult task in practice and our data reflect the real-world differences that exist between different applied criteria. In this respect, the difference in OS between institutions, which is an unambiguous endpoint, is harder to explain, but could be related to hospital-specific factors such as patient selection. For example, patients from center 3 had on average significantly larger PTVs than patients from the other institutions (all $\mathrm{p}<0.0001)$. The negative selection was obvious 
Table 3 Results of the multivariable Cox model analyses on imputed datasets

\begin{tabular}{|c|c|c|c|c|}
\hline \multirow[t]{3}{*}{ Variable } & \multicolumn{4}{|c|}{ Overall survival ( $\mathrm{N}=484,394$ events) } \\
\hline & \multirow[t]{2}{*}{ HR } & \multicolumn{2}{|l|}{$95 \% \mathrm{CI}$} & \multirow[t]{2}{*}{$\mathrm{p}$-value } \\
\hline & & Lower & Upper & \\
\hline Age (10 years increase) & 1.100 & 0.989 & 1.220 & 0.128 \\
\hline Gender: Female vs. Male & 1.240 & 0.997 & 1.540 & 0.036 \\
\hline KPS & 0.983 & 0.974 & 0.992 & $0.00010^{*}$ \\
\hline \multicolumn{5}{|l|}{ Main tumor localization } \\
\hline Parietal vs. frontal & 0.820 & 0.601 & 1.120 & 0.534 \\
\hline Temporal vs. frontal & 0.994 & 0.749 & 1.320 & 0.985 \\
\hline Multiple vs. frontal & 1.200 & 0.862 & 1.680 & 0.247 \\
\hline Other vs. frontal & 1.140 & 0.777 & 1.670 & 0.207 \\
\hline $\begin{array}{l}\text { Surgery extent: Gross total vs. not gross total } \\
\text { resection }^{\mathrm{a}}\end{array}$ & 0.641 & 0.513 & 0.801 & $<0.0001^{*}$ \\
\hline MGMT hypermethylation: Yes vs. No & 0.415 & 0.329 & 0.524 & $<0.0001 *$ \\
\hline IDH mutation: Yes vs. No & 0.393 & 0.247 & 0.625 & $<0.0001 *$ \\
\hline PTV $\left(100 \mathrm{~cm}^{3}\right.$ increase $)$ & 1.090 & 1.020 & 1.180 & $0.00095^{*}$ \\
\hline RT protocol: HFRT vs. NFRT & 1.210 & 0.916 & 1.600 & 0.108 \\
\hline \multicolumn{5}{|l|}{ Temozolomide } \\
\hline Simultaneous and sequential vs. none & 0.583 & 0.380 & 0.896 & 0.016 \\
\hline Simultaneous or sequential vs. none & 1.120 & 0.682 & 1.850 & 0.528 \\
\hline Steroids: Yes vs. No & 1.340 & 1.040 & 1.710 & 0.094 \\
\hline Salvage: Yes vs. No & 0.607 & 0.476 & 0.776 & $<0.0001^{*}$ \\
\hline Frailty (clinic) & & & & 0.010 \\
\hline
\end{tabular}

Hazard ratios and p-values are pooled estimates from 100 Cox frailty models with a normal distribution for the random effects. Each model had been fitted to one of 100 datasets with slightly different imputations of missing variables (see Materials and Methods for details)

${ }^{a}$ Not gross total resection comprises incomplete resection, debulking and biopsy

CI Confidence interval; HR Hazard ratio

$* \mathrm{p}<0.01$ (statistically significant) in this patient cohort also by admission of HFRT in case of proximity to the brainstem. In addition, there might have been other unmeasured differences, so that the use of frailty models was a reasonable choice. This was confirmed by the importance of the frailty terms in multivariable modelling (Tables 3 and 4).

Another modality to reduce treatment time besides HFRT is hypofractionated accelerated radiation therapy. The use of hypofractionated protocols has been established in several randomized controlled trials [55-58]. This method is however primarily recommended for elderly patients and its role in the treatment of GB in younger individuals and those with good prognosis requires further research [59]. The other potentially interesting point of hypofractionation is the theoretical possibility of overcoming immanent or acquired radioresistance of tumor cells [44]. An alternative way of overcoming radioresistance could be a local dose escalation in biologically active tumor volumes, albeit the clinical data of dose escalation are needed to be proven in phase 3 trials [60]. Another possibility could be an intensification of chemotherapy regimens in selected patients which may also improve the treatment results with acceptable toxicity [61, 62].

Despite the large sample size, this study had several limitations. First, the presented data are retrospective in nature, which implies potential uncertainties in some variables, missing data, as well as the possibility of systematic confounding and biases. We took account of the problem of missing variables by using multiple imputation by chained equations, which is preferred over just using the data with complete cases because it makes better use of the full information within the data [45]. Sensitivity analysis with only the complete cases yielded quantitatively similar results as the imputed dataset analysis and therefore confirmed the latter, although uncertainties in regression coefficients were larger, as would be expected due to the smaller sample size. For example, $I D H$ mutation status was a highly significant predictor of OS in multivariable regression on the imputed datasets but failed to reach the significance threshold in multivariable regression on the original dataset. Steroid administration was associated with worse OS in multivariable regression on both the 
Table 4 Results of the multivariable Cox model analyses on complete observations only

\begin{tabular}{|c|c|c|c|c|}
\hline \multirow[t]{3}{*}{ Variable } & \multicolumn{4}{|c|}{ Overall survival $(\mathrm{N}=226,177$ events $)$} \\
\hline & \multirow[t]{2}{*}{ HR } & \multicolumn{2}{|l|}{$95 \% \mathrm{CI}$} & \multirow[t]{2}{*}{ p-value } \\
\hline & & Lower & Upper & \\
\hline Age (10 years increase) & 1.143 & 0.970 & 1.347 & 0.112 \\
\hline Gender: Female vs. Male & 1.367 & 0.971 & 1.925 & 0.073 \\
\hline KPS & 0.994 & 0.981 & 1.008 & 0.412 \\
\hline \multicolumn{5}{|l|}{ Main tumor localization } \\
\hline Parietal vs. frontal & 1.101 & 0.667 & 1.817 & 0.706 \\
\hline Temporal vs. frontal & 1.281 & 0.749 & 1.320 & 0.265 \\
\hline Multifocal vs. frontal & 0.978 & 0.593 & 1.614 & 0.932 \\
\hline Other vs. frontal & 1.585 & 0.854 & 2.942 & 0.144 \\
\hline $\begin{array}{l}\text { Surgery extent: Gross total vs. not gross total } \\
\text { resection }^{\mathrm{a}}\end{array}$ & 0.554 & 0.394 & 0.778 & $0.00064 *$ \\
\hline MGMT hypermethylation: Yes vs. No & 0.429 & 0.304 & 0.605 & $<0.0001 *$ \\
\hline IDH mutation: Yes vs. No & 0.320 & 0.124 & 0.824 & 0.018 \\
\hline PTV $\left(100 \mathrm{~cm}^{3}\right.$ increase $)$ & 1.281 & 1.110 & 1.493 & $0.0015^{*}$ \\
\hline RT protocol: HFRT vs. NFRT & 1.019 & 0.653 & 1.589 & 0.935 \\
\hline \multicolumn{5}{|l|}{ Temozolomide } \\
\hline Simultaneous and sequential vs. none & 0.660 & 0.333 & 1.308 & 0.234 \\
\hline Simultaneous or sequential vs. none & 2.076 & 0.958 & 4.499 & 0.064 \\
\hline Steroids: Yes vs. No & 1.298 & 0.888 & 1.899 & 0.178 \\
\hline Salvage: Yes vs. No & 0.452 & 0.312 & 0.656 & $<0.0001^{*}$ \\
\hline Frailty (clinic) & & & & 0.029 \\
\hline
\end{tabular}

CI Confidence interval; HR Hazard ratio; PFS Progression-free survival

${ }^{a}$ Not gross total resection comprises incomplete resection, debulking and biopsy

*Statistically significant $(\mathrm{p}<0.01)$ imputed and original datasets but failed to reach the significance threshold. Nevertheless, the obtained hazard ratio $>1$ is consistent with the detrimental effects of steroids found by Pitter et al. [52] which Klement and Champ [16] have attributed in part to the well-known effects of corticosteroids to raise blood glucose levels. In general, it is reassuring for the quality of our data that the hazard ratios of all variables are consistent with their expected effects on PFS and OS which are known from previous studies and tumor biology.

Another limitation is that the tolerability of the treatments was not directly evaluated because of the retrospective nature of this work. The need for steroids was assessed as an indicator of both tumor progression and treatment-related brain edema. Steroid administration was more frequent in the HFRT group. However, since prophylactic steroid administration was also performed, it cannot be considered an accurate surrogate parameter of toxicity. Previous data from Kaul et al. [39] and Lewitzki et al. [40] reported good tolerance of simultaneous TMZ and HFRT.

In conclusion, our multicenter analysis suggests that radiochemotherapy with HFRT and TMZ is a safe option for patients wishing to shorten their treatment time and does not affect OS, even in the context of larger tumors or poorer performance status. MGMT hypermethylation, smaller tumor size, and salvage therapy were confirmed to have the most significant positive impact on OS. To the best of our knowledge, both HFRT protocols were well tolerated without excessive acute or late toxicity, albeit no dedicated analysis was performed due to the retrospective nature. Analyses of neurocognition and quality of life in particular should also be performed in the future for a better assessment of tolerance. The rate of treatment interruptions was low in all protocol groups.

Acknowledgements Felix Ehret is participant in the BIH Charite Junior Clinician Scientist Program funded by the Charité - Universitätsmedizin Berlin and Berlin Institute of Health at Charité (BIH).

Author contributions All authors contributed to the study conception and design. Material preparation, data collection and analysis were performed by VL, RJK, IP, DC, FE and RS. The first draft of the manuscript was written by RJK and VL and all authors commented on previous versions of the manuscript. All authors read and approved the final manuscript.

Funding Open Access funding enabled and organized by Projekt DEAL. The authors did not receive support from any organization for the submitted work. 
Data availability The datasets generated during and/or analyzed during the current study are available from the corresponding author on reasonable request.

\section{Declarations}

Conflict of interest The authors declare that this analysis has been conducted without any financial or other relevant conflicts of interest.

Animal research statement There was no animal research performed.

Consent to participate statement Ethical approval was waived by the local Ethics Committees of University Clinic of Würzburg, University Clinic Charité Berlin and University Clinic of Freiburg in view of the retrospective nature of the study and all the procedures being performed were part of the routine care.

Consent to publish statement Statistical analysis, procession and publishing of complete anonymized patient data were approved by the local Ethics Committees of University Clinic of Würzburg, University Clinic Charité Berlin and University Clinic of Freiburg.

Planned reproducibility statement Our research group is planning a prospective observational trial to confirm the findings.

Clinical trials registration This research study was conducted retrospectively from data obtained for clinical purposes. No trial protocol and registration are applicable.

Open Access This article is licensed under a Creative Commons Attribution 4.0 International License, which permits use, sharing, adaptation, distribution and reproduction in any medium or format, as long as you give appropriate credit to the original author(s) and the source, provide a link to the Creative Commons licence, and indicate if changes were made. The images or other third party material in this article are included in the article's Creative Commons licence, unless indicated otherwise in a credit line to the material. If material is not included in the article's Creative Commons licence and your intended use is not permitted by statutory regulation or exceeds the permitted use, you will need to obtain permission directly from the copyright holder. To view a copy of this licence, visit http://creativecommons.org/licenses/by/4.0/.

\section{References}

1. Ostrom QT, Patil N, Cioffi G, Waite K, Kruchko C, BarnholtzSloan JS (2020) CBTRUS statistical report: primary brain and other central nervous system tumors diagnosed in the United States in 2013-2017. Neuro Oncol 22:1-96. https://doi.org/10. 1093/neuonc/noaa200

2. Kraywinkel K, Spix C (2019) Epidemiology of primary brain tumors in children and adults in Germany. Onkologe 25:5-9. https://doi.org/10.1007/s00761-018-0501-1

3. Adeberg S, Bernhardt D, Harrabi SB, Uhl M, Paul A, Bougatf N et al (2017) Sequential proton boost after standard chemoradiation for high-grade glioma. Radiother Oncol 125:266-272. https://doi. org/10.1016/j.radonc.2017.09.040

4. Stupp R, Taillibert S, Kanner A, Read W, Steinberg DM, Lhermitte B et al (2017) Effect of tumor-treating fields plus maintenance temozolomide vs maintenance temozolomide alone on survival in patients with glioblastoma a randomized clinical trial. JAMA - J Am Med Assoc 318:2306-2316. https://doi.org/10. 1001/jama.2017.18718
5. Lakomy R, Kazda T, Selingerova I, Poprach A, Pospisil P, Belanova R et al (2020) Real-world evidence in glioblastoma: Stupp's regimen after a decade. Front Oncol 10:840. https://doi. org/10.3389/fonc. 2020.00840

6. Curran WJ Jr, Scott CB, Horton J, Nelson JS, Weinstein AS, Fischbach AJ et al (1993) Recursive partitioning analysis of prognostic factors in three Radiation Therapy Oncology Group malignant glioma trials. J Natl Cancer Inst 85:704-710. https://doi.org/10. 1093/jnci/85.9.704

7. Niyazi M, Adeberg S, Kaul D, Boulesteix AL, Bougatf N, Fleischmann DF et al (2018) Independent validation of a new reirradiation risk score (RRRS) for glioma patients predicting post-recurrence survival: A multicenter DKTK/ROG analysis. Radiother Oncol 127:121-127. https://doi.org/10.1016/j.radonc.2018.01.011

8. Lee J, Park SH, Kim YZ (2018) Prognostic evaluation of neurological assessment of the neuro-oncology scale in glioblastoma patients. Brain Tumor Res Treat 6:22. https://doi.org/10.14791/ btrt.2018.6.e1

9. Scott CB, Scarantino C, Urtasun R, Movsas B, Jones CU, Simpson JR et al (1998) Validation and predictive power of Radiation Therapy Oncology Group (RTOG) recursive partitioning analysis classes for malignant glioma patients: a report using RTOG 90-06. Int J Radiat Oncol Biol Phys 40:51-55. https://doi.org/10. 1016/S0360-3016(97)00485-9

10. Siegel EM, Nabors LB, Thompson RC, Olson JJ, Browning JE, Madden MH et al (2013) Prediagnostic body weight and survival in high grade glioma. J Neurooncol 114:79-84. https://doi.org/10. 1007/s11060-013-1150-2

11. Potharaju M, Mangaleswaran B, Mathavan A, John R, Thamburaj $\mathrm{V}$, Ghosh S et al (2018) Body mass index as a prognostic marker in glioblastoma multiforme: a clinical outcome. Int J Radiat Oncol Biol Phys 102:204-209. https://doi.org/10.1016/j.ijrobp.2018.05. 024

12. Jones LW, Ali-Osman F, Lipp E, Marcello JE, McCarthy B, McCoy L et al (2010) Association between body mass index and mortality in patients with glioblastoma mutliforme. Cancer Causes Control 21:2195-2201. https://doi.org/10.1007/ s10552-010-9639-x

13. Derr RL, Ye X, Islas MU, Desideri S, Saudek CD, Grossman SA (2009) Association between hyperglycemia and survival in patients with newly diagnosed glioblastoma. J Clin Oncol 27:1082-1086. https://doi.org/10.1200/JCO.2008.19.1098

14. Tieu MT, Lovblom LE, McNamara MG, Mason W, Laperriere N, Millar B-A et al (2015) Impact of glycemia on survival of glioblastoma patients treated with radiation and temozolomide. J Neurooncol 124:119-126. https://doi.org/10.1007/s11060-015-1815-0

15. Adeberg S, Bernhardt D, Foerster R, Bostel T, Koerber SA, Mohr A et al (2016) The influence of hyperglycemia during radiotherapy on survival in patients with primary glioblastoma. Acta Oncol (Madr) 55:201-207. https://doi.org/10.3109/0284186X.2015. 1043397

16. Klement RJ, Champ CE (2017) Corticosteroids compromise survival in glioblastoma in part through their elevation of blood glucose levels. Brain 140:e16. https://doi.org/10.1093/brain/aww324

17. Voss M, Wenger KJ, Von MN, Bojunga J, Vetter M (2021) Short - term fasting in glioma patients: analysis of diet diaries and metabolic parameters of the ERGO2 trial. Eur J Nutr. https://doi.org/ 10.1007/s00394-021-02666-1

18. Mirimanoff RO, Gorlia T, Mason W, Van Den Bent MJ, Kortmann RD, Fisher B et al (2006) Radiotherapy and temozolomide for newly diagnosed glioblastoma: recursive partitioning analysis of the EORTC 26981/22981-NCIC CE3 phase III randomized trial. J Clin Oncol 24:2563-2569. https://doi.org/10.1200/JCO.2005. 04.5963

19. Combs SE, Thilmann C, Edler L, Debus J, Schulz-Ertner D (2005) Efficacy of fractionated stereotactic reirradiation in recurrent 
gliomas: Long-term results in 172 patients treated in a single institution. J Clin Oncol 23:8863-8869. https://doi.org/10.1200/ JCO.2005.03.4157

20. Quick J, Gessler F, Dützmann S, Hattingen E, Harter PN, Weise LM et al (2014) Benefit of tumor resection for recurrent glioblastoma. J Neurooncol 117:365-372. https://doi.org/10.1007/ s11060-014-1397-2

21. Stupp R, Masen WP, van den Bent MJ, Weller M, Fisher B, Taphoorn MJB et al (2005) Radiotherapy plus concomitant and adjuvant temozolomide for glioblastoma. N Engl J Med 352:987-996

22. Hegi ME, Diserens A-C, Gorlia T, Hamou M-F, de Tribolet N, Weller M et al (2005) MGMT gene silencing and benefit from temozolomide in glioblastoma. N Engl J Med 352:997-1003. https://doi.org/10.1056/nejmoa043331

23. Beiko J, Suki D, Hess KR, Fox BD, Cheung V, Cabral M et al (2014) IDH1 mutant malignant astrocytomas are more amenable to surgical resection and have a survival benefit associated with maximal surgical resection. Neuro Oncol 16:81-91. https://doi. org/10.1093/neuonc/not 159

24. Wee CW, Kim E, Kim N, Kim IA, Kim TM, Kim YJ et al (2017) Novel recursive partitioning analysis classification for newly diagnosed glioblastoma: a multi-institutional study highlighting the MGMT promoter methylation and IDH1 gene mutation status. Radiother Oncol 123:106-111. https://doi.org/10.1016/j.radonc. 2017.02.014

25. Wee CW, Kim IH, Park CK, Kim JW, Dho YS, Ohka F et al (2018) Validation of a novel molecular RPA classification in glioblastoma (GBM-molRPA) treated with chemoradiation: a multi-institutional collaborative study. Radiother Oncol 129:347-351. https://doi.org/10.1016/j.radonc.2018.09.001

26. Vuong HG, Nguyen TQ, Ngo TNM, Nguyen HC, Fung KM, Dunn IF (2020) The interaction between TERT promoter mutation and MGMT promoter methylation on overall survival of glioma patients: A meta-analysis. BMC Cancer 20:897. https:// doi.org/10.1186/s12885-020-07364-5

27. Arita H, Matsushita Y, Machida R, Yamasaki K, Hata N, Ohno $M$ et al (2020) TERT promoter mutation confers favorable prognosis regardless of $1 \mathrm{p} / 19 \mathrm{q}$ status in adult diffuse gliomas with IDH1/2 mutations. Acta Neuropathol Commun 8:201. https:// doi.org/10.1186/s40478-020-01078-2

28. Walker MD, Strike TA, Sheline GE (1979) An analysis of doseeffect relationship in the radiotherapy of malignant gliomas. Int J Radiat Oncol Biol Phys 5:1725-1731. https://doi.org/10.1016/ 0360-3016(79)90553-4

29. Thames HD, Peters LT, Withers HR, Fletcher GH (1983) Accelerated fractionation vs hyperfractionation: rationales for several treatments per day. Int J Radiat Oncol Biol Phys 9:127-138. https://doi.org/10.1016/0360-3016(83)90089-5

30. Withers HR (1985) Biologic basis for altered fractionation schemes. Cancer 55:2086-2095. https://doi.org/10.1002/10970142(19850501)55:9+\%3c2086::AID-CNCR2820551409\% 3e3.0.CO;2-1

31. Curran WJ, Scott CB, Nelson JS, Weinstein AS, Phillips TL, Murray K et al (1992) A randomized trial of accelerated hyperfractionated radiation therapy and bis-chlorethyl nitrosourea for malignant glioma. A preliminary report of radiation therapy oncology group 83-02. Cancer 70:2909-2917

32. Werner-Wasik M, Scott CB, Nelson DF, Gaspar LE, Murray KJ, Fischbach JA et al (1996) Final report of a phase I/II trial of hyperfractionated and accelerated hyperfractionated radiation therapy with carmustine for adults with supratentorial malignant gliomas: Radiation therapy oncology group study 83-02. Cancer 77:1535-1543. https://doi.org/10.1002/(SICI)10970142(19960415)77:8\%3c1535::AID-CNCR17\%3e3.0.CO;2-0
33. Lutterbach J, Weigel P, Guttenberger R, Hinkelbein W (1999) Accelerated hyperfractionated radiotherapy in 149 patients with glioblastoma multiforme. Radiother Oncol 53:49-52. https:// doi.org/10.1016/S0167-8140(99)00128-0

34. Nieder C, Nestle U, Ketter R, Kolles H, Gentner SJ, Steudel WI et al (1999) Hyperfractionated and accelerated-hyperfractionated radiotherapy for glioblastoma multiforme. Radiat Oncol Investig 7:36-41. https://doi.org/10.1002/(SICI)15206823(1999)7:1\%3c36::AID-ROI5\%3e3.0.CO;2-O

35. Prados MD, Wara WM, Sneed PK, McDermott M, Chang SM, Rabbitt J et al (2001) Phase III trial of accelerated hyperfractionation with or without difluromethylornithine (DFMO) versus standard fractionated radiotherapy with or without DFMO for newly diagnosed patients with glioblastoma multiforme. Int J Radiat Oncol Biol Phys 49:71-77. https://doi.org/10.1016/ S0360-3016(00)01458-9

36. Ali AN, Zhang P, Yung WKA, Chen Y, Movsas B, Urtasun RC et al (2018) NRG oncology RTOG 9006: a phase III randomized trial of hyperfractionated radiotherapy (RT) and BCNU versus standard RT and BCNU for malignant glioma patients. J Neurooncol 137:39-47. https://doi.org/10.1007/s11060-017-2558-x

37. Withers HR, Peters LJ, Thames HD, Fletcher GH (1982) Hyperfractionation. Int J Radiat Oncol Biol Phys 8:1807-1809. https://doi.org/10.1016/0360-3016(82)90307-8

38. Stupp R, Hegi ME, Mason WP, van den Bent MJ, Taphoorn MJ, Janzer RC et al (2009) Effects of radiotherapy with concomitant and adjuvant temozolomide versus radiotherapy alone on survival in glioblastoma in a randomised phase III study: 5-year analysis of the EORTC-NCIC trial. Lancet Oncol 10:459-466. https://doi.org/10.1016/S1470-2045(09)70025-7

39. Kaul D, Florange J, Badakhshi H, Grün A, Ghadjar P, Exner S et al (2016) Accelerated hyperfractionation plus temozolomide in glioblastoma. Radiat Oncol 11:1-7. https://doi.org/10.1186/ s13014-016-0645-3

40. Lewitzki V, Klement RJ, Kosmala R, Lisowski D, Flentje M, Polat B (2019) Accelerated hyperfractionated radiochemotherapy with temozolomide is equivalent to normofractionated radiochemotherapy in a retrospective analysis of patients with glioblastoma. Radiat Oncol 14:227

41. Wen PY, Macdonald DR, Reardon DA, Cloughesy TF, Sorensen AG, Galanis E et al (2010) Updated response assessment criteria for high-grade gliomas: Response assessment in neuro-oncology working group. J Clin Oncol 28:1963-1972. https://doi.org/10. 1200/JCO.2009.26.3541

42. Duchateau L, Janssen P (2008) The frailty model, 1st edn. Springer, New York

43. Austin PC (2017) A tutorial on multilevel survival analysis: methods, models and applications. Int Stat Rev 85:185-203. https://doi. org/10.1111/insr.12214

44. Sterne JAC, White IR, Carlin JB, Spratt M, Royston P, Kenward MG et al (2009) Multiple imputation for missing data in epidemiological and clinical research: potential and pitfalls. BMJ Br Med J 338:b2393. https://doi.org/10.1136/bmj.b2393

45. Chowdhry AK, Gondi V, Pugh SL (2021) Missing data in clinical studies. Int J Radiat Oncol Biol Phys 110:1267-1271. https://doi. org/10.1016/j.ijrobp.2021.02.042

46. Van Buuren S, Groothuis-Oudshoorn K (2011) mice: multivariate imputation by chained equations in R. J Stat Softw 45:1-67. https://doi.org/10.1177/0962280206074463

47. Held L, Ott M (2018) On p-values and Bayes factors. Annu Rev Stat Its Appl 5:393-419

48. Bandyopadhyay PS, Brittan G Jr, Taper ML (2016) Belief, Evidence, and Uncertainty: Problems of Epistemic Inference, 1st edn. Springer, Basel

49. R Core Team. R: A language and environment for statistical computing. 2021. 
50. Pedicini P, Fiorentino A, Simeon V, Tini P, Chiumento C, Pirtoli L et al (2014) Clinical radiobiology of glioblastoma multiforme: Estimation of tumor control probability from various radiotherapy fractionation schemes. Strahlenther Onkol 190:925-932. https:// doi.org/10.1007/s00066-014-0638-9

51. Lee SP, Leu MY, Smathers JB, McBride WH, Parker RG, Withers HR (1995) Biologically effective dose distribution based on the linear quadratic model and its clinical relevance. Int J Radiat Oncol Biol Phys 33:375-389. https://doi.org/10.1016/03603016(95)00162-R

52. Pitter KL, Tamagno I, Alikhanyan K, Hosni-Ahmed A, Pattwell SS, Donnola S et al (2016) Corticosteroids compromise survival in glioblastoma. Brain 139:1458-1471. https://doi.org/10.1093/ brain/aww046

53. Chinopoulos C, Seyfried TN (2018) Mitochondrial substrate-level phosphorylation as energy source for glioblastoma: review and hypothesis. ASN Neuro 10:1759091418818261. https://doi.org/ $10.1177 / 1759091418818261$

54. Chesnelong C, Chaumeil MM, Blough MD, Al-Najjar M, Stechishin OD, Chan JA et al (2014) Lactate dehydrogenase A silencing in IDH mutant gliomas. Neuro Oncol 16:686-695. https://doi. org/10.1093/neuonc/not243

55. Perry JR, Laperriere N, O'Callaghan CJ, Brandes AA, Menten J, Phillips C et al (2017) Short-Course Radiation plus Temozolomide in Elderly Patients with Glioblastoma. N Engl J Med 376:1027-1037. https://doi.org/10.1056/nejmoa1611977

56. Malmström A, Grønberg BH, Marosi C, Stupp R, Frappaz D, Schultz H et al (2012) Temozolomide versus standard 6-week radiotherapy versus hypofractionated radiotherapy in patients older than 60 years with glioblastoma: the Nordic randomised, phase 3 trial. Lancet Oncol 13:916-926. https://doi.org/10.1016/ S1470-2045(12)70265-6

57. Roa W, Brasher PMA, Bauman G, Anthes M, Bruera E, Chan A et al (2004) Abbreviated course of radiation therapy in older patients with glioblastoma multiforme: a prospective randomized clinical trial. J Clin Oncol 22:1583-1588. https://doi.org/10.1200/ JCO.2004.06.082

58. Navarria P, Pessina F, Tomatis S, Soffietti R, Grimaldi M, Lopci E et al (2017) Are three weeks hypofractionated radiation therapy (HFRT) comparable to six weeks for newly diagnosed glioblastoma patients? Results of a phase II study. Oncotarget 8:6769667708. https://doi.org/10.18632/ONCOTARGET.18809

59. Liao G, Zhao Z, Yang H, Li X (2019) Efficacy and safety of hypofractionated radiotherapy for the treatment of newly diagnosed glioblastoma multiforme: a systematic review and meta-analysis. Front Oncol 9:1017. https://doi.org/10.3389/fonc.2019.01017

60. Laack NN, Pafundi D, Anderson SK, Kaufmann T, Lowe V, Hunt $\mathrm{C}$ et al (2021) Initial results of a phase 2 trial of 18F-DOPA PETguided dose-escalated radiation therapy for glioblastoma. Int $\mathrm{J}$ Radiat Oncol Biol Phys 110:1383-1395. https://doi.org/10.1016/j. ijrobp.2021.03.032

61. Herrlinger U, Tzaridis T, Mack F, Steinbach JP, Schlegel U, Sabel M et al (2019) Lomustine-temozolomide combination therapy versus standard temozolomide therapy in patients with newly diagnosed glioblastoma with methylated MGMT promoter (CeTeG/NOA-09): a randomised, open-label, phase 3 trial. Lancet 393:678-688. https://doi.org/10.1016/S0140-6736(18)31791-4

62. Esteyrie V, Dehais C, Martin E, Carpentier C, Uro-Coste E, Figarella-Branger D et al (2021) Radiotherapy plus procarbazine, lomustine, and vincristine versus radiotherapy plus temozolomide for IDH-mutant anaplastic astrocytoma: a retrospective multicenter analysis of the French POLA Cohort. Oncologist 26:e838-e846. https://doi.org/10.1002/onco.13701

Publisher's Note Springer Nature remains neutral with regard to jurisdictional claims in published maps and institutional affiliations. 